\title{
ASSESSMENT OF MOTOR DEVELOPMENT OF PRESCHOOL CHILDREN WITH SPECIAL EDUCATION NEEDS
}

\author{
Vassiliki Rigai, \\ Anastasia Misirli, \\ Akrivi Komessariou \\ Department of Educational Sciences and \\ Early Childhood Education, \\ University of Patras, Rio Patras, \\ Greece
}

\begin{abstract}
:
Assessment of motor development in preschool children has become increasingly important with the recent acknowledgement that motor impairment/deficit is linked with cognitive, language, social, and emotional difficulties. As there is lack of evidence regarding motor development and early intervention in children with special education needs (SEN), the purpose of this study was to assess the motor development of preschool students with SEN within the educational context to allow their teachers to design appropriate physical education activities to improve students' motor proficiency. In the present study, the Peabody Developmental Motor Scales - Second Edition test battery was used with five groups of students with different SEN: (a) Autism Spectrum Disorder, (b) Down syndrome, (c) cerebral palsy, (d) mental disability, and (e) specific learning difficulties. Students were grouped on the basis of specific characteristics, such as gender and SEN, and statistically significant differences between groups were sought. Differences in the difficulties encountered during the subtests by children in different SEN groups were found, suggesting that evidence of certain motor weaknesses are more likely for children with specific SEN. An unsatisfactory level in overall performance in gross, fine, and total motor quotients confirmed the delayed motor development of students with SEN. The paper concludes with recommendations for an appropriate evaluative measure and early intervention programmes for children with specific motor impairments.
\end{abstract}

Keywords: motor proficiency, gross and fine motor skills, early childhood, children with special education needs

i Correspondence: email vriga@upatras.gr 


\section{Introduction}

In the early years of a child's development, measuring the acquisition of motor skills has been reported as vital for their further smooth physical, cognitive, and social development (Cools, De Martelaer, Samaey, \& Andries, 2009; Giagazoglou et al., 2011). At the international level, research has identified a relationship between a child's motor and cognitive development (Diamond, 2000). Based on those findings, the scientific community focused on developing movement assessment instruments to identify problems and plan early intervention programmes. The most well-knows instruments are the (a) Movement Assessment Battery for Children (MABC-2), (b) Test of Gross Motor Development (TGMD-3), (c) Bruininks-Oseretsky test of Motor Proficiency (BOT-2), (d) Peabody Developmental Motor Scales (PDMS-2), (e) Körperkoordinationtest für Kinder (KTK), (f) Maastrichtse Motoriek Test (MMT), and (g) Bayley Scales of Infant and Toddler Development (Bayley-3).

As Cools et al. (2009) have described, research has mainly focused on motor impairment and motor deficits, and only a few studies have focused on assessing the development and performance of a child's fundamental movement skills within a school context. Indeed, only a few recent studies (Nonis \& Jernice, 2014; Zawi, Lian, \& Abdullah, 2014) have been conducted assessing the level of motor development among preschool children with special education needs (SEN) in a school context. Most studies have focused on the implementation of intervention programmes and the investigation of their effectiveness (Erim \& Caferoğlu, 2017; Karim \& Mohammed, 2015; Niklasson, Norlander, Niklasson, \& Rasmussen, 2017). However, according to Visser et al. (2012), early findings of developmental problems among children with SEN can minimise the long-term effects of those problems and support the social integration of such children. Such physiological special needs create deficits in cognitive development, communication problems, an inability to develop motors, and difficulties in establishing social relations and carrying out everyday activities (Asonitou, Koutsouki, Kourtessis, \& Charitou, 2012; Giagazoglou et al., 2011; Kourtessis et al., 2008).

The majority of extant studies draw two main conclusions: (a) the motor development of children with SEN is slower than that of children with typical development (Nonis \& Jernice, 2014) and (b) the use of appropriate motor development intervention programmes can make a positive contribution to improve the motor proficiency of children with SEN (Erim \& Caferoğlu, 2017; Niklasson et al., 2017; Nonis \& Jernice, 2014; Valentini \& Rudisill, 2004).

Combining the limited motor proficiency of children with SEN and its relevance to everyday life and their normal development reveals the need for the present investigation. This study assessed the motor development of preschool students with SEN within the educational context to allow their teachers to design appropriate physical education activities to improve students' motor proficiency. 


\section{Material and Methods}

The present paper presents a case study of preschool students with SEN in inclusive units and special preschools in a region in western Greece. The motor development and ability of preschoolers with SEN was recorded to raise awareness among preschool teachers of the importance of creating appropriate motor programmes.

\subsection{Participants}

The population of the present study included children diagnosed with Autism Spectrum Disorder (ASD), Down syndrome, cerebral palsy, mental disability, and specific learning difficulties. This diagnosis was determined by special centers recognised by the Greek Ministry of Education. All ethical issues concerning the rights of research participants were taken into account during the study. Authorisation and permission were initially obtained from the Greek Ministry of Education to carry out this research. All of the teachers of all the inclusive units and special preschools were informed, and written consent was sought from the parents and students.

The study was carried out in nine educational settings, of which three were special preschools and the other six were inclusive units. In the study region, 41 students with SEN attended preschool education, of which 36 participated in the research. Two students were not examined because the parents did not give written consent, and for three students, the difficulty in securing their cooperation due to the nature of the SEN made the examination inapplicable.

The age of students scaled to a mean of 73.22 months (SD=8.401). In terms of gender, boys $\left(\mathrm{N}_{b}=24\right)$ outnumbered girls $\left(\mathrm{N}_{\mathrm{g}}=12\right)$ 2:1. Students were divided into five groups according to the official diagnosis of each specific SEN: (a) the first group consisted of 16 students with ASD; (b) the second group, 5 students with Down syndrome; (c) the third group, 3 students with cerebral palsy; (d) the fourth group, 3 students with mental disabilities; and (e) the fifth group, 9 students with specific learning difficulties.

\subsection{Instruments}

To collect the data in this study, the Peabody Developmental Motor Scales - Second Edition (PDMS-2) test battery was used. This battery reflects the students' level of gross and fine motor skills within six motor subtests: (a) stationary, (b) locomotion, (c) object manipulation, (d) grasping, (e) visual-motor integration, and (f) reflexes (Fewell \& Folio, 2000). The final subtest was not included because these skills are acquired during the first twelve months of a child's life. According to Fewell and Folio (2000), the PDMS-2 is a valid and reliable tool suitable not only for students with typical development, but also for evaluating students with SEN. Several studies have highlighted the effectiveness of the PDMS-2 when applied to children with delays or disorders in motor development (Tieman, Palisano, \& Sutlive, 2005; Van Hartingsveldt, Cup, \& Oostendorp, 2005) and as a tool to assess the effectiveness of teaching interventions in physical education programmes (Karim \& Mohammed, 2015; Wang 2004). 
The PDMS-2 scale consists of 249 items with detailed information on how to select and assess appropriate items corresponding to the motor age of the child, rather than the chronological age. The test battery enables raw scores to be converted and interpreted in different ways, including equivalent motor age, the percentile rank, standard scores, and the composite quotient. These modified scores were used to analyse the data in this research. Another characteristic of the PDMS-2 is that it provides an intervention programme of 104 motor teaching and therapy activities as a follow-up to the assessment of a child's motor development (Fewell \& Folio, 2000).

\subsection{Procedure}

After obtaining permission to conduct the study from the Ministry of Education, we contacted and informed preschools about the research. Meetings were arranged with preschools teachers to discuss the content of the research, summarise the tool, distribute consent forms for parents, and determine the schedule for the researcher to follow with the teachers in charge. The research was completed within four months, after 36 visits to all schools lasting a total of 39 hours.

The qualified researcher in the test battery seriously considered the differences in class environments in the schools. The approach was adapted to the individual needs of each child using play to facilitate involvement. If a child was not cooperative, the intervention was stopped and attempted again later on the same or a different day (within the next five days). Intervention measurements were performed in a private non distracting room within each school and student competence was measured during a one-on-one testing session.

\subsection{Statistical Analysis}

Data were analysed at two levels in quantitative and qualitative terms. Initially, data on students' motor performance were quantified with the help of SPSS v.21 software for the five included subtests (stationary, locomotion, object manipulation, grasping, and visualmotor integration) and for the three global indexes of motor performance called composites (gross, fine, and total motor quotients). Whether the age of the students tested corresponded to the motor age resulting from their performance in all of the above categories was also examined. To interpret the findings, we used the auxiliary tables provided by the battery (Fewell \& Folio, 2000) to convert the raw scores into standard and quotient scores (Table 1).

Table 1: Guide to interpreting PDMS-2 subtest standard and quotient scores

\begin{tabular}{lcc}
\hline Standard Scores & Quotient Scores & Description \\
\hline $\mathbf{1 7 - 2 0}$ & $131-165$ & Very Superior \\
\hline $\mathbf{1 5 - 1 6}$ & $121-130$ & Superior \\
\hline $\mathbf{1 3 - 1 4}$ & $111-120$ & Above Average \\
\hline $\mathbf{8 - 1 2}$ & $90-110$ & Average \\
\hline $\mathbf{6 - 7}$ & $80-89$ & Below Average \\
\hline $\mathbf{4 - 5}$ & $70-79$ & Poor \\
\hline $\mathbf{1 - 3}$ & $35-69$ & Very Poor \\
\hline
\end{tabular}


The participating students were then grouped on the basis of specific characteristics, such as gender and SEN, and the results of these groups were compared to determine whether there were any statistically significant differences.

The second level of analysis concerned the qualitative presentation of the findings for student performance in the test battery and was structured in two parts. The first part involved the identification of the specific difficulties encountered in the subtests by children in each group to obtain information on the likelihood of presenting certain motor weaknesses for each SEN. The second part, not presented here, the individual cases for each student were analysed and the teachers of the schools were trained to increase their capacity to plan appropriate early intervention programmes.

\section{Results}

\subsection{Quantitative Analysis}

The descriptive statistics showed that the students achieved the highest score for fine motor skills, by a difference of five points. However, the overall performance in gross, fine, and total motor quotients did not reach a satisfactory level, which confirmed the delayed motor development of students with SEN (Table 2).

Table 2: Average value of standard scores in the five subtests and three quotients

\begin{tabular}{lccccc}
\hline & $\mathbf{N}$ & Min. & Max. & Mean & SD \\
\hline Standard score stationary & 34 & 3 & 10 & 5.00 & 2.015 \\
\hline Standard score locomotion & 34 & 3 & 8 & 4.53 & 1.419 \\
\hline Standard score object manipulation & 34 & 1 & 10 & 6.15 & 2.120 \\
\hline Standard score grasping & 36 & 1 & 11 & 5.81 & 3.250 \\
\hline Standard score visual-motor integration & 36 & 1 & 14 & 5.72 & 3.195 \\
\hline Gross motor quotient & 34 & 51 & 89 & 69.32 & 10.522 \\
\hline Fine motor quotient & 36 & 46 & 115 & 74.31 & 18.910 \\
\hline Total motor quotient & 34 & 44 & 97 & 69.44 & 13.977 \\
\hline
\end{tabular}

Table 3 shows the differences between boys and girls in relation to the average standard scores recorded in the five subtests. Girls appeared to perform better in the stationary and grasping subtests, and boys performed better in the object manipulation subtest. Girls also achieved higher scores than boys in the locomotion and visual-motor integration subtests, as can be seen in the average standard scores for these two groups. Regarding the general picture of motor development by gender, the mean value of the total motor quotient for girls appeared to be higher than that for boys. The greatest deviation between genders appeared in the fine motor quotient, with girls having a higher mean value. After an independent samples t-test (as indicated by the $\mathrm{p}$ value in the last column of Table 3), however, gender appeared to have no statistically significant impact on children's motor proficiency in any of the five subtests or the three quotients $(\mathrm{p}>0.05)$. 
Table 3: Comparison of average standard scores and quotients between genders and statistical significance of gender in motor performance

\begin{tabular}{|c|c|c|c|c|c|c|c|c|}
\hline & \multirow{3}{*}{$\begin{array}{c}\text { Gender } \\
\text { Boys } \\
\text { Girls }\end{array}$} & \multirow{3}{*}{$\begin{array}{l}\mathbf{N} \\
23 \\
11 \\
\end{array}$} & \multirow{3}{*}{$\begin{array}{c}\mathbf{M} \\
4.87 \\
5.27 \\
\end{array}$} & \multirow{3}{*}{\begin{tabular}{c|} 
SD \\
2.00 \\
2.10 \\
\end{tabular}} & \multicolumn{2}{|c|}{ CI $(95 \%)$} & \multirow{3}{*}{$\begin{array}{c}\mathbf{t} \\
-0.54\end{array}$} & \multirow{3}{*}{$\begin{array}{c}\mathbf{P} \\
0.59\end{array}$} \\
\hline \multirow{2}{*}{ Standard score stationary } & & & & & 4.00 & 5.74 & & \\
\hline & & & & & 3.86 & 6.68 & & \\
\hline \multirow{2}{*}{ Standard score locomotion } & Boys & 23 & 4.52 & 1.44 & 3.90 & 5.15 & \multirow{2}{*}{-0.04} & \multirow{2}{*}{0.96} \\
\hline & Girls & 11 & 4.55 & 1.44 & 3.58 & 5.51 & & \\
\hline \multirow{2}{*}{ Standard score object manipulation } & Boys & 23 & 6.43 & 2.12 & 5.51 & 7.36 & \multirow{2}{*}{1.15} & \multirow{2}{*}{0.25} \\
\hline & Girls & 11 & 5.55 & 2.06 & 4.16 & 6.93 & & \\
\hline \multirow{2}{*}{ Standard score grasping } & Boys & 24 & 5.38 & 3.06 & 4.28 & 6.85 & \multirow{2}{*}{-1.12} & \multirow{2}{*}{0.26} \\
\hline & Girls & 12 & 6.67 & 3.57 & 5.00 & 9.37 & & \\
\hline \multirow{2}{*}{$\begin{array}{l}\text { Standard score visual-motor } \\
\text { integration }\end{array}$} & Boys & 24 & 5.71 & 3.48 & 4.44 & 7.39 & \multirow{2}{*}{-0.03} & \multirow{2}{*}{0.97} \\
\hline & Girls & 12 & 5.75 & 2.66 & 4.63 & 7.74 & & \\
\hline \multirow{2}{*}{ Gross motor quotient } & Boys & 23 & 69.65 & 10.51 & 65.10 & 74.20 & \multirow{2}{*}{0.26} & \multirow{2}{*}{0.79} \\
\hline & Girls & 11 & 68.64 & 11.01 & 61.24 & 76.03 & & \\
\hline \multirow{2}{*}{ Fine motor quotient } & Boys & 24 & 73.25 & 19.09 & 66.39 & 82.48 & \multirow{2}{*}{-0.46} & \multirow{2}{*}{0.64} \\
\hline & Girls & 12 & 76.42 & 19.18 & 67.47 & 90.89 & & \\
\hline \multirow{2}{*}{ Total motor quotient } & Boys & 23 & 68.87 & 14.35 & 62.66 & 75.08 & \multirow{2}{*}{-0.34} & \multirow{2}{*}{0.73} \\
\hline & Girls & 11 & 70.64 & 13.75 & 61.39 & 79.88 & & \\
\hline
\end{tabular}

In the second level of data processing, we examined the possible impact of SEN on children's motor proficiency, but the number of students in each group was too small to allow us to perform ANOVA. We therefore carried out a descriptive analysis of average scores for the five categories of SEN (Table 4). In stationary, grasping, and visual-motor integration subtests, students with specific learning difficulties and students with mental disability appeared to perform better. Students with mental retardation scored high in the locomotion subtest, whereas students with specific learning difficulties and students with Down syndrome scored high in the object manipulation subtest. In the gross motor quotient, the highest mean value was recorded for children with specific learning difficulties and children with mental disabilities, followed by children with Down syndrome and ASD, while the lowest score was recorded for the child with cerebral palsy. In the fine motor quotient, again, students with specific learning difficulties achieved the highest scores, followed by those with mental disabilities and ASD, whereas lower scores were found among children with Down syndrome and cerebral palsy. Finally, children with specific learning difficulties and mental disabilities achieved higher scores in the total motor quotient, followed by children with ASD and Down syndrome. The lowest score was recorded for the child with cerebral palsy.

Table 4: Comparison of average standard scores and quotients between the five groups

\begin{tabular}{llccccc}
\hline & SEN & N & M & SD & \multicolumn{2}{c}{ CI (95\%) } \\
\hline & ASD & 16 & 4.81 & 2.25 & 3.61 & 6.02 \\
Standard score & Down syndrome & 5 & 5.00 & 1.58 & 3.04 & 6.96 \\
stationary & Cerebral palsy & 1 & 3.00 & & & \\
& Mental disability & 3 & 5.33 & 2.30 & -0.40 & 11.07 \\
& Specific learning difficulties & 9 & 5.44 & 1.94 & 3.95 & 6.94 \\
\hline Standard score & ASD & 16 & 4.44 & 1.67 & 3.55 & 5.33 \\
locomotion & Down syndrome & 5 & 4.00 & 1.00 & 2.76 & 5.24 \\
\hline
\end{tabular}




\begin{tabular}{|c|c|c|c|c|c|c|}
\hline & Cerebral palsy & 1 & 3.00 & & & \\
\hline & Mental disability & 3 & 5.33 & 0.57 & 3.90 & 6.77 \\
\hline & Specific learning difficulties & 9 & 4.89 & 1.26 & 3.91 & 5.86 \\
\hline \multirow{5}{*}{$\begin{array}{l}\text { Standard score } \\
\text { object manipulation }\end{array}$} & ASD & 16 & 5.50 & 2.44 & 4.19 & 6.81 \\
\hline & Down syndrome & 5 & 6.80 & 2.28 & 3.97 & 9.63 \\
\hline & Cerebral palsy & 1 & 6.00 & & & \\
\hline & Mental disability & 3 & 6.33 & 1.52 & 2.54 & 10.13 \\
\hline & Specific learning difficulties & 9 & 6.89 & 1.53 & 5.71 & 8.07 \\
\hline \multirow{5}{*}{$\begin{array}{l}\text { Standard score } \\
\text { grasping }\end{array}$} & ASD & 16 & 5.75 & 3.53 & 3.87 & 7.63 \\
\hline & Down syndrome & 5 & 3.80 & 1.09 & 2.44 & 5.16 \\
\hline & Cerebral palsy & 3 & 2.00 & 1.73 & -2.30 & 6.30 \\
\hline & Mental disability & 3 & 7.00 & 2.00 & 2.03 & 11.97 \\
\hline & Specific learning difficulties & 9 & 7.89 & 2.66 & 5.84 & 9.94 \\
\hline \multirow{5}{*}{$\begin{array}{l}\text { Standard score } \\
\text { visual-motor integration }\end{array}$} & ASD & 16 & 5.88 & 3.86 & 3.82 & 7.93 \\
\hline & Down syndrome & 5 & 4.20 & 0.44 & 3.64 & 4.76 \\
\hline & Cerebral palsy & 3 & 2.33 & 2.30 & -3.40 & 8.07 \\
\hline & Mental disability & 3 & 6.33 & 1.15 & 3.46 & 9.20 \\
\hline & Specific learning difficulties & 9 & 7.22 & 2.53 & 5.27 & 9.17 \\
\hline \multirow{5}{*}{$\begin{array}{l}\text { Gross motor } \\
\text { quotient }\end{array}$} & ASD & 16 & 67.25 & 12.08 & 60.81 & 73.69 \\
\hline & Down syndrome & 5 & 69.60 & 9.76 & 57.48 & 81.72 \\
\hline & Cerebral palsy & 1 & 61.00 & & & \\
\hline & Mental disability & 3 & 72.33 & 9.29 & 49.25 & 95.41 \\
\hline & Specific learning difficulties & 9 & 72.78 & 8.92 & 65.92 & 79.64 \\
\hline \multirow{5}{*}{$\begin{array}{l}\text { Fine motor } \\
\text { quotient }\end{array}$} & ASD & 16 & 74.25 & 21.93 & 62.56 & 85.94 \\
\hline & Down syndrome & 5 & 64.00 & 4.24 & 58.73 & 69.27 \\
\hline & Cerebral palsy & 3 & 53.00 & 12.12 & 22.88 & 83.12 \\
\hline & Mental disability & 3 & 80.00 & 9.16 & 57.23 & 102.77 \\
\hline & Specific learning difficulties & 9 & 85.33 & 14.50 & 74.19 & 96.48 \\
\hline \multirow{5}{*}{$\begin{array}{l}\text { Total motor } \\
\text { quotient }\end{array}$} & ASD & 16 & 67.56 & 16.91 & 58.55 & 76.58 \\
\hline & Down syndrome & 5 & 64.00 & 7.90 & 54.18 & 73.82 \\
\hline & Cerebral palsy & 1 & 60.00 & & & \\
\hline & Mental disability & 3 & 73.00 & 8.88 & 50.92 & 95.08 \\
\hline & Specific learning difficulties & 9 & 75.67 & 11.53 & 66.80 & 84.53 \\
\hline
\end{tabular}

\subsection{Qualitative Analysis}

Individual assessment provided insight into the common motor characteristics (motor deficits) of children within the same SEN group. Nevertheless, the SEN seemed to have no significant effect on children's motor proficiency based on their initial scores.

$A S D$ students faced several difficulties, mainly in two items from the stationary subtest: 'standing on one foot' and 'standing on tiptoes'. In the locomotion subtest, they had difficulty in several exercises, such as 'walking up and down stairs', in 'body agility', in 'keeping balance', 'walking on a line', 'jumping forward, up or down', 'jumping hurdles', and 'standing on tiptoes'. Regarding the object manipulation subtest, the most difficult exercises for this group were: 'catching ball', 'throwing ball over or underhand', and 'hitting target'. This group performed better in the grab skills, although they had difficulty with 'unbuttoned and buttoned buttons' and 'touching fingers' (thumb to other fingers) because of limited finger flexibility. Finally, they had difficulty in several items from the visual-motor integration subtest, such as coordinating hand movements for 
more accuracy when 'drawing lines, vertical lines and simple geometric shapes on paper', the orientation of shapes on paper, handling scissors for 'cutting lines and simple geometric shapes', and copying a construction given to them for 'building towers'.

The performance of students with Down syndrome was quite different, but showed weaknesses similar to those of the ASD students, in the stationary subtest, particularly for 'imitating movements', 'standing on one foot' and 'standing on tiptoes' for a specific period of time without the body deviating from the vertical axis. In the locomotion subtest, a number of difficulties were noted for 'standing' and 'walking on a line' either with the whole tread or on tiptoes, 'jumping forward, up, down' and 'jumping hurdles', 'walking up and down stairs' due to lack of movement stability, and a lack of agility to increase 'running speed'. Regarding the object manipulation subtest, some items were difficult for these children, especially items that involved the hand movement accuracy for the 'catching ball' subtest, after throwing and after bouncing, the 'throwing ballunderhand', and the 'hitting target' directly and after bouncing the ball. There were three main items in the grasping subtest that this group did not respond to at all, namely, the 'unbuttoning/buttoning buttons' (which showed the rigidity of their fingers), the 'grasping marker', and the 'touching fingers'. The variety of performance observed in the visual-motor integration subtest makes it difficult to identify common weaknesses in this group of students. The prevailing score was therefore considered the most representative of the group's performance. In particular, we identified difficulties in 'using marker' (to draw vertical, horizontal or intersecting lines and simple geometric shapes such as circles), in 'building towers' (with cubes), in coordinating finger movements for 'cutting paper' (along a straight line without leaving its boundaries), and in 'stringing and lacing'. It was impossible to identify any common elements that caused difficulties in the group of students with cerebral palsy, because one student was high functioning and the two others were in a wheelchair and had functional use of only the left upper arm. The latter two students were not subjected to the gross motor skills subtests, and in the fine motor skills, only the ability of the functional arm was assessed, so the results are presented separately. The high-functioning student encountered difficulties only in 'standing on one foot' and 'standing on tiptoes' in the stationary subtest, but found the following subtests difficult: 'walking sideways', 'walking up and down stairs', 'standing', 'walking on a line', and 'jumping up, down and forward'. In the object manipulation subtest, he rarely managed to accomplish the following tasks: 'catch the ball after throwing', 'hitting ball', 'hitting ball overhand and underhand', and 'hitting the target after ball is bounced'. In grasping skills, he found the following tasks difficult: 'unbuttoning and buttoning buttons', 'grasping markers', and 'using fingers'. In the visual-motor integration subtest, it was difficult for this student to complete the tasks 'stringing and lacing' of a cloth or through beads, to copy a construction made with cubes 'building towers', to copy shapes and lines 'using markers', and to cut a line on paper 'cutting paper'.

The two students in wheelchairs had difficulties in coordinating hand movements for the tasks 'reach an object and pull it toward them', 'extend the functional hand in a direction', and 'grasping multiple objects', as well as achieving accuracy of movement when 'placing a small object in a vessel'. Their weaknesses included limited coordination 
of torso movements on 'turn' to the left to achieve visual contact with stimulus in that direction. The greatest weakness in the grasping subtest was observed in controlling movements of the functional hand for 'holding object with the palm' for some time and 'making gestures with a certain direction or for a specific purpose', as well as in the accuracy of finger movements when 'grasping smaller objects'. All these difficulties yielded a motor development level corresponding to children aged 0-14 months.

The items in the stationary subtest that were more difficult for mentally disabled students included 'standing on one foot' for a few seconds and the exact performance in 'imitating movements'. In the locomotion subtest, this group found it difficult to complete tasks such as: 'walking up and down stairs' with independence and stability of movement, 'walking on tiptoes', 'jumping forward' at a distance, 'jumping up' higher and 'jumping down' from a height (e.g. high chair), 'turning jump', 'jumping sideways', 'running speed and agility', and 'skipping', as well as engaging reflexes for early stop during running and 'galloping' and 'hopping'. In the object manipulation subtest, they had difficulty in 'catching ball', 'kicking ball' (using force), 'hitting target', and 'catching bounced ball' with accuracy, as well as in controlling the cadence of a bouncing ball, so that it touches the ground and then bounces over the wall. Very few weaknesses appeared in the grasping subtest and in particular the 'unbuttoning and buttoning buttons' at agility and speed and the 'touching fingers'. Finally, in the visual-motor integration subtest, most skills were fully developed in the students, although there were weaknesses in hand movements for 'drawing shapes with accuracy', in 'cutting paper' (with scissors following the corners lines of a shape), in 'folding paper' accurately, and in 'building towers' with cubes from recall without a visual representation of the original.

The nine students with specific learning difficulties mostly had not developed stationary skills and did not meet the criteria of full acquisition for several exercises such as 'standing on one foot' (right and left), movement stability in 'standing on tiptoes' for duration without the body wobbling or heels touching the ground, and in 'imitating movements'. In the locomotion subtest, these students also found difficult it to achieve a reduction in 'speed' and an immediate stop following a stimulus given to them, they failed 'walking on a line' (forward and backward), they had no power to 'jump forward and up', they were unable to perform 'jumping down' from a chair, and they had difficulty in walking on a straight line without falling over or touching the ground with their heels. In the object manipulation subtest, while this group showed satisfactory performance in catching the ball, they had difficulty in performing the 'catching ball' movement with a small ball. They also had difficulty in controlling the movements and power of the hands in 'kicking ball', 'hitting target', and 'bouncing ball', although they had consolidated the technique. No one in this group succeeded in catching a bounced ball. In the grasping subtest, students had difficulties with only two items, the 'unbuttoning and buttoning buttons' in a short period of time, a skill requiring both flexibility and understanding of the space in which the buttons change levels on the cloth, and 'touching fingers' because of a lack of ability to rotate their fingers more quickly. Finally, in the visual-motor integration subtest, the difficult items for these students were quite specific; they experienced difficulty 'drawing lines, angles, and multi-sided shapes', 
maintaining precision when changing paper orientation for 'cutting paper' (with scissors), 'folding paper', and recalling from memory a 'construction' to build it with cubes.

In considering the motor performance of all students according to SEN type, we noticed common difficulties for specific skills. In Table 5, the results for the motor age of the students in the five groups for specific motor skills are presented.

Table 5: Motor age of participants in specific skills

\begin{tabular}{|c|c|c|c|c|c|}
\hline Skills & ASD & $\begin{array}{c}\text { Down } \\
\text { syndrome }\end{array}$ & $\begin{array}{c}\text { Cerebral } \\
\text { palsy }\end{array}$ & $\begin{array}{c}\text { Mental } \\
\text { disability }\end{array}$ & $\begin{array}{c}\text { Specific learning } \\
\text { difficulties }\end{array}$ \\
\hline $\begin{array}{l}\text { Standing on } \\
\text { one foot }\end{array}$ & $\begin{array}{l}37-48 \\
\mathrm{M}^{*}\end{array}$ & $31-42 \mathrm{M}$ & $31-36 \mathrm{M}$ & $43-54 \mathrm{M}$ & $43-48 \mathrm{M}$ \\
\hline $\begin{array}{l}\text { Standing on } \\
\text { tiptoes }\end{array}$ & $\begin{array}{l}37-48 \\
\mathrm{M}\end{array}$ & $49-54 \mathrm{M}$ & $43-48 \mathrm{M}$ & $43-54 \mathrm{M}$ & $49-54 \mathrm{M}$ \\
\hline $\begin{array}{l}\text { Imitating } \\
\text { movements }\end{array}$ & $\mathrm{UD}^{*}$ & $55-60 \mathrm{M}$ & $19-24 \mathrm{M}$ & $55-60 \mathrm{M}$ & $55-60 \mathrm{M}$ \\
\hline $\begin{array}{l}\text { Walking } \\
\text { sideways }\end{array}$ & $\mathrm{C}^{*}$ & C & $19-24 \mathrm{M}$ & $\mathrm{C}$ & $\mathrm{C}$ \\
\hline $\begin{array}{l}\text { Standing \& } \\
\text { walking on a line }\end{array}$ & $\begin{array}{l}37-42 \\
M\end{array}$ & $37-42 \mathrm{M}$ & $25-30 \mathrm{M}$ & $43-54 \mathrm{M}$ & $37-42 \mathrm{M}$ \\
\hline $\begin{array}{l}\text { Walking up } \\
\text { stairs }\end{array}$ & $\begin{array}{l}31-36 \\
M\end{array}$ & $25-36 \mathrm{M}$ & $25-30 \mathrm{M}$ & $31-36 \mathrm{M}$ & $\mathrm{C}$ \\
\hline $\begin{array}{l}\text { Walking } \\
\text { down stairs }\end{array}$ & $\begin{array}{l}43-48 \\
M\end{array}$ & $43-48 \mathrm{M}$ & $25-30 \mathrm{M}$ & $\mathrm{C}$ & $\mathrm{C}$ \\
\hline Running & $\begin{array}{l}37-42 \\
M\end{array}$ & $37-42 \mathrm{M}$ & $25-30 \mathrm{M}$ & $37-48 \mathrm{M}$ & $43-48 \mathrm{M}$ \\
\hline $\begin{array}{l}\text { Jumping } \\
\text { forward }\end{array}$ & $\begin{array}{l}31-36 \\
\mathrm{M}\end{array}$ & $31-42 \mathrm{M}$ & $31-36 \mathrm{M}$ & $43-54 \mathrm{M}$ & $43-48 \mathrm{M}$ \\
\hline $\begin{array}{l}\text { Jumping } \\
\text { up }\end{array}$ & $\begin{array}{l}25-30 \\
\mathrm{M}\end{array}$ & $25-30 \mathrm{M}$ & $25-30 \mathrm{M}$ & $43-48 \mathrm{M}$ & $25-30 \mathrm{M}$ \\
\hline $\begin{array}{l}\text { Jumping } \\
\text { down }\end{array}$ & $\begin{array}{l}31-36 \\
M\end{array}$ & $31-36 \mathrm{M}$ & $19-24 \mathrm{M}$ & $31-36 \mathrm{M}$ & $25-36 \mathrm{M}$ \\
\hline $\begin{array}{l}\text { Walking } \\
\text { on tiptoes }\end{array}$ & $\begin{array}{l}25-30 \\
\mathrm{M}\end{array}$ & $31-36 \mathrm{M}$ & UD & $25-36 \mathrm{M}$ & $31-36 \mathrm{M}$ \\
\hline $\begin{array}{l}\text { Jumping } \\
\text { hurdles }\end{array}$ & $\begin{array}{l}31-36 \\
M\end{array}$ & $31-36 \mathrm{M}$ & UD & $\mathrm{C}$ & $55-60 \mathrm{M}$ \\
\hline Hopping & UD & UD & UD & $43-54 \mathrm{M}$ & UD \\
\hline Rolling forward & UD & $\mathrm{NE}^{* *}$ & UD & 49-54 M & UD \\
\hline Galloping & UD & UD & UD & $49-54 \mathrm{M}$ & UD \\
\hline $\begin{array}{l}\text { Turning jump \& } \\
\text { jumping sideways }\end{array}$ & UD & UD & UD & $49-60 \mathrm{M}$ & UD \\
\hline $\begin{array}{l}\text { Running speed \& } \\
\text { agility }\end{array}$ & UD & UD & UD & $55-60 \mathrm{M}$ & UD \\
\hline Skipping & UD & UD & UD & $55-60 \mathrm{M}$ & UD \\
\hline $\begin{array}{l}\text { Catching } \\
\text { ball }\end{array}$ & $\begin{array}{l}31-42 \\
\mathrm{M}\end{array}$ & $49-54 \mathrm{M}$ & $37-54 \mathrm{M}$ & $43-54 \mathrm{M}$ & $49-54 \mathrm{M}$ \\
\hline Hitting ball & $\mathrm{C}$ & $43-48 \mathrm{M}$ & $43-48 \mathrm{M}$ & $\mathrm{C}$ & $\mathrm{C}$ \\
\hline Kicking ball & $\begin{array}{l}61-72+ \\
M\end{array}$ & C & $61-72+\mathrm{M}$ & $61-72+\mathrm{M}$ & $61-72+\mathrm{M}$ \\
\hline
\end{tabular}




\begin{tabular}{llcccc}
\hline \hline $\begin{array}{l}\text { Hitting } \\
\text { target }\end{array}$ & $\begin{array}{l}49-54 \\
\mathrm{M}\end{array}$ & $49-54 \mathrm{M}$ & $49-54 \mathrm{M}$ & $37-42 \mathrm{M}$ & $49-54 \mathrm{M}$ \\
\hline $\begin{array}{l}\text { Bouncing } \\
\text { ball }\end{array}$ & $\begin{array}{l}49-54 \\
\mathrm{M}\end{array}$ & $49-54 \mathrm{M}$ & $49-54 \mathrm{M}$ & $49-54 \mathrm{M}$ & $49-54 \mathrm{M}$ \\
\hline $\begin{array}{l}\text { Unbuttoning/buttoning } \\
\text { buttons }\end{array}$ & $\begin{array}{l}37-48 \\
\mathrm{M}\end{array}$ & $37-48 \mathrm{M}$ & $37-48 \mathrm{M}$ & $37-48 \mathrm{M}$ & $43-48 \mathrm{M}$ \\
\hline $\begin{array}{l}\text { Grasping marker } \\
\text { with one hand }\end{array}$ & $\mathrm{C}$ & $49-54 \mathrm{M}$ & $49-54 \mathrm{M}$ & $\mathrm{C}$ & $\mathrm{C}$ \\
\hline $\begin{array}{l}\text { Touching } \\
\text { fingers }\end{array}$ & $\begin{array}{l}49-54 \\
\mathrm{M}\end{array}$ & $49-54 \mathrm{M}$ & $49-54 \mathrm{M}$ & $49-54 \mathrm{M}$ & $49-54 \mathrm{M}$ \\
\hline $\begin{array}{l}\text { Using } \\
\text { markers }\end{array}$ & $\begin{array}{l}37-54 \\
\mathrm{M}\end{array}$ & $31-42 \mathrm{M}$ & $31-42 \mathrm{M}$ & $37-54 \mathrm{M}$ & $43-54 \mathrm{M}$ \\
\hline Building towers & $\mathrm{C}$ & $31-42 \mathrm{M}$ & $\mathrm{C}$ & $\mathrm{C}$ & $\mathrm{C}$ \\
\hline $\begin{array}{l}\text { Cutting } \\
\text { paper }\end{array}$ & $\begin{array}{l}37-42 \\
\mathrm{M}\end{array}$ & $37-42 \mathrm{M}$ & $37-42 \mathrm{M}$ & $49-54 \mathrm{M}$ & $49-54 \mathrm{M}$ \\
\hline Stringing \& lacing & $\mathrm{C}$ & $37-42 \mathrm{M}$ & $25-30 \mathrm{M}$ & $\mathrm{C}$ & $\mathrm{C}$ \\
\hline $\begin{array}{l}\text { Building } \\
\text { objects }\end{array}$ & $\begin{array}{l}25-36 \\
\mathrm{M}\end{array}$ & $25-36 \mathrm{M}$ & $25-36 \mathrm{M}$ & $49-54 \mathrm{M}$ & $43-54 \mathrm{M}$ \\
\hline $\begin{array}{l}\text { Folding } \\
\text { paper }\end{array}$ & $\begin{array}{l}55-60 \\
\mathrm{M}\end{array}$ & $55-60 \mathrm{M}$ & $55-60 \mathrm{M}$ & $55-60 \mathrm{M}$ & $55-60 \mathrm{M}$ \\
\hline
\end{tabular}

${ }^{*} \mathrm{M}=$ Months, $\mathrm{UD}=$ Under Development $\mathrm{C}=$ Consolidated

${ }^{* *} \mathrm{NE}=$ Not examined in children with Down syndrome. The physiology of this SEN does not allow application of the rolling forward item (Fewell and Folio 2000b).

***Student without cerebral palsy.

\section{Discussion}

The results of the quantitative analysis confirmed the assumption that the motor development in students with SEN would be slow, which is in line with the results of prior researches (Erim \& Caferoğlu, 2017; Niklasson et al., 2017; Nonis \& Jernice, 2014; Valentini \& Rudisill, 2004; Visser et al., 2012). The average motor age (Mage=37.61 months) for all of the students involved was obviously lower than their chronological age (Mage=73.22 months) and corresponded to the motor development level of a three-yearold child. Interpretation of the standard scores for the motor development of these children could be assessed as 'poor' with regard to the stationary, locomotion, grasping, and visual-motor integration subtests and 'below satisfactory' for the object manipulation subtest. According to the battery test, the gross and total motor quotients for the population should be considered 'very poor' and the fine motor quotient, 'poor'.

Considering the potential influence of gender on students' motor proficiency, the data collected showed little gender differentiation. In more detail, the standard scores for both boys and girls expressed similar levels of motor development for the locomotion and visual-motor integration subtests. In contrast, differences were identified in the standard scores of the other subtests, with girls demonstrating higher stationary and grasping skills, while boys seemed to perform better when executing object manipulation skills. These differences were not statistically significant based on the administered t-test in independent subjects of the population. Many researchers have argued that girls seem 
to perform better in tests of stationary, locomotion, and visual-motor integration skills, while boys appear to perform better in tests of object manipulation skills, without regard to the presence of SEN (Dourou, Komessariou, Riga, \& Lavidas, 2017; Fisher et al., 2005; Foulkes et al., 2015; Hardy et al., 2010; Kourtessis et al., 2008; Livesey, Coleman, \& Piek, 2007; Saraiva, Rodrigues, Cordovil, \& Barreiros, 2013; Venetsanou \& Kambas, 2016).

Recent research has tended to attribute apparent gender-based performance differences to socio-cultural and socio-economic factors, as in most societies gender stereotypes prevail for games that are socially acceptable for children to engage in (Frömel, Stelzer, Groffik, \& Ernest, 2008; Giagazoglou, 2013; Kourtessis et al., 2008; Livesey et al., 2007; Saraiva et al., 2013; Spessato, Gabbard, Valentini, \& Rudisill, 2013). Thus, through free play, children practise different skills: boys tend to be more involved in intense physical activity and team sports, while girls tend to engage more in aerobic gymnastics, dolls (role playing), and painting (Frömel et al., 2008; Giagazoglou, 2013). However, despite these differences, the overall picture of motor proficiency for both genders tested here was considered to be 'below satisfactory' and mostly 'poor'.

In addition, girls appeared to perform better in tests of fine and total mobility, as shown in their quotients rates, while boys' quotients were higher for gross mobility. It should be noted, however, that for gross mobility, the performance for both gender groups was characterised as 'very poor', while fine mobility was characterised as 'poor'. However, different evidence emerged regarding total mobility and gender, as boys' average performance was characterised 'very poor' while girls' average performance was characterised as 'poor'. Setting these gender differences aside, however, pre-schoolers with SEN, overall, were identified as having delayed motor development.

Our data are of particular interest, however, in interpreting the potential influence of SEN on the motor development of children, as the motor performance of the participants varied according to SEN type. Students with specific learning difficulties appeared to excel in more developed mobility, followed - with decreasing assessed performance values - by students with mental disability, ASD, Down syndrome, and cerebral palsy. The level of functionality permitted by each SEN appeared to be important for the motor development of the children, as it determined the ability of the child to control movement. Where the SEN allowed higher motor functionality, students demonstrated greater evolution in their motor skills.

The qualitative analysis of the results showed that all students, regardless of the weaknesses in each group, did not respond to some items. In particular, in the gross motor quotient, students with SEN lacked the ability to control their weight distribution, which resulted in body imbalance. Weakness of the body muscles may be a possible cause for this (Fewell \& Folio, 2000). Due to the physiology of the SEN, the affected children do not exercise often and are therefore not in good physical condition, which results in poor levels of strength and resistance, such that they cannot perform exercises to practise and improve motor skills. For example, some students had no developed skills in standing on one and/or both feet and walking on tiptoes, and those skills proved very demanding. This led to the assumption that special education should perhaps focus more on performing static balance, as it proved to be an important skill for a child's performance 
in everyday life and self-autonomy. To cite another example, in jumping up, the children found it difficult to make the jumping movement in conjunction with the hand movement to touch the wall at a certain height above the head. This lack of coordination was also observed in other tasks requiring concomitant response to more than one stimulus (e.g. throwing a ball over- or underhand at a wall).

Regarding the fine motor quotient, the children with SEN had difficulty using their fingers independently to perform complex fine movements, such as unbuttoning and buttoning buttons or touching fingers between them. The children also appeared to have particular difficulty in managing small objects such as felt boxes, small cubes and scissors. This indicates a lack of coordination for the finger movements, which are often a result of problems in the neurological system among children with SEN (Fewell \& Folio, 2000). As in the case of gross motor skills, it was observed that the fine motor skills the students lacked require both a simultaneous response to more than one stimulus and motor coordination (e.g. simultaneously holding cloth and passing buttons through it, holding paper with one hand and using scissors to cut, capturing a structure in memory and rebuilding it, capturing a geometric shape or other drawing into memory and redrawing). One possible interpretation for the difficulty the participants experienced in responding to complex items is that the nature of the SEN does not allow these children to conceive of more than one piece of information at a time. Indeed, the majority of people with SEN are characterised by deficits in sense, emotional behaviour, and language development (Stasinos, 2016).

Another possible interpretation relates to school life and the stimuli received by the children every day. According to several researchers (Giagazoglou, 2013; Giagazoglou et al., 2011; Hardy et al., 2010; Wang, 2004) the more a skill is practised through physical exercise and related games, the more sophisticated it becomes. The results of our research suggest that SEN students do not appear to be systematically involved in organised activities in the school framework that target the development of gross motor skills, such as balance (static and dynamic), jumping, ball handling (target shooting, bouncing), and the use of fine motor skills, such as buttoning/unbuttoning and the management of pens and scissors. Such activities are organised by class teachers, who should receive additional training in facilitating these activities among children with SEN (Wang, 2004).

All students demonstrated that they were happy to participate in the various motor activities. The researcher, before the tests, tried to develop a friendly relationship with the children by organising games. Three important issues emerged during the assessment. First, the instructions given for performing the tasks should be very simple, because it appeared that decoding the command, rather than the task itself, sometimes made accomplishing the task difficult for the child. According to the literature (Dordić, Tubić, \& Jakšić, 2016), inadequate development of the nervous system affects uptake and ability to understand information. Second, it is important to motivate the student and create operational conditions to stimulate their interest in participation during organised activities. Third, to involve the child in physical education activities every day, 
appropriate conditions should be created in terms of environment (e.g. physical education learning area) and stimulation (e.g. use of multi-sensory materials).

\subsection{Conclusion}

Individual physical education programmes are based on already acquired skills that are the starting point for any intervention and do not focus on difficulties as such. It is particularly important that physical activities at school focus on the individual level (i.e. on the needs of each child), because children need to develop fundamental movement skills at their own personal pace. The role of teachers is extremely important in implementing interventions or carrying out an activity, as they should be encouraging towards children and patient and flexible in terms of providing rich stimuli and changing activities when needed. It is also very important that the teacher supports interventions to meet the different needs of their students using appropriate means (Valentini \& Rudisill, 2004). The most important thing is that programmes should be meaningful for children, who should not see them as tests, but engage primarily in the pleasure of participating in the activities.

This study confirmed, to a certain extent, the assumed suitability of applying this battery test to children with SEN, as the SEN type did not appear to be a particular obstacle to successful use of the battery, which is in line with the literature (Karim \& Mohammed, 2015; Tieman et al., 2005; Van Hartingsveldt et al., 2005; Visser et al., 2012).

\subsection{Limitations}

Although the results of this study were related to the motor development of almost all of the children with SEN in an entire area (region) in Greece, the sample number was too small to allow generalisation. As qualitative analysis of our results has shown, it is difficult to group the motor weaknesses of children diagnosed with the same syndrome, because many developmental and learning difficulties coexist in each child; their development is thus influenced by many factors, such as individual treatments in private sector. Further longitudinal and intervention studies within the school framework and with a larger sample could allow for more thorough insight into the motor development of children with SEN. As this study was the first of its kind to be carried out in a Greek preschool setting, the applicability of its results is therefore limited by its exploratory character.

The PDMS-2 may be appropriate for use as an evaluative measure to measure change in motor development over time, to identify a delay in motor skill acquisition compared to typically developing same-aged peers, to provide useful information regarding motor development for children with motor delays but not for children with specific neuromotor impairments Tieman, Palisano, \& Sutlive, 2005).

\subsection{Implications for Future Research}

Notwithstanding its limitations, this study provides valuable information about the level of motor development in children with SEN attending preschool, and useful conclusions can be drawn. The study highlights the need for teachers to provide regular structured 
opportunities, games, and physical activities to enhance the motor development of these children within the daily school schedule. Future studies could design a motor intervention programme or targeted interventions based on the results of this research and explore the effectiveness of such interventions within the preschool. Preschool teachers could also be involved in normative data collection for future studies to familiarise them with modern tools for assessing children's motor development to meet the needs of the students in their class. Because the school setting plays a vital role in enhancing the development of children's motor skills, is important for further studies to be undertaken within the school framework with the help of teachers and school management.

\section{Acknowledgements}

The authors would like to gratefully acknowledge the children and teachers who are participating in this research.

\section{About the Authors}

Vassiliki Riga, PhD, is an Assistant Professor of Theatrical Expression, Rhythm and Movement in Early Childhood Education at the University of Patras (Greece). Her research focuses on issues pertaining to the role of physical education in preschool age, physical literacy, body and theatrical expression, body culture studies, and embodied/somatic learning in education.

Anastasia Misirli works as a head-teacher at the Greek Preschool London and completed her MA in Special Educational Needs at the Brunel University and her PhD in Early Childhood Education, Robotics and Programming at the University of Patras (Greece).

Akrivi Komessariou works as a kindergarten teacher and completed her Master Studies in 'Language, art and culture in education' in the Department of Educational Sciences and Early Childhood Education, University of Patras (Greece).

\section{References}

Asonitou, K., Koutsouki, D., Kourtessis, T., \& Charitou, S. (2012). Motor and cognitive performance differences between children with and without developmental coordination disorder (DCD). Research in Developmental Disabilities, 33(4): 9961005. https://doi.org/10.1016/j.ridd.2012.01.008.

Cools, W., De Martelaer, K., Samaey, C., \& Andries, C. (2009). Movement skill assessment of typically developing preschool children: A review of seven movement skill assessment tools. Journal of Sports Science and Medicine, 8(2): 154-168.

Diamond, A. (2000). Close interrelation of motor development and cognitive development and of the cerebellum and prefrontal cortex. Child Development, 71(1): 44-56. https://doi.org/10.1111/1467-8624.00117. 
Dordić, V., Tubić, T., \& Jakšić, D. (2016). The relationship between physical, motor, and intellectual development of preschool children. Procedia - Social and Behavioral Sciences, 233: 3-7. https://doi.org/10.1016/j.sbspro.2016.10.114.

Dourou, E., Komessariou, A., Riga, V., \& Lavidas, K. (2017). Assessment of gross and fine motor skills in preschool children using the Peabody Developmental Motor Scales Instrument. European Psychomotricity Journal, 9(1): 89-113.

Erim, G., \& Caferoğlu, M. (2017). Determining the motor skills development of mentally retarded children through the contribution of visual arts. Universal Journal of Educational Research, 5(8): 1300-1307. https://doi.org/10.13189/ujer.2017.050803.

Fewell, R., \& Folio, R. (2000a). Peabody development motor scales: Examiner's manual - Guide to item administration - Motor activities program (2nd ed.). London: Pearson.

Fisher, A., Reilly, J. J., Kelly, L. A., Montgomery, C., Williamson, A., Paton, J. Y., \& Grant, S. (2005). Fundamental movement skills and habitual physical activity in young children. Medicine $\mathcal{E}$ Science in Sports $\mathcal{E}$ Exercise, 37(4): 684-688. https://doi.org/10.1249/01.mss.0000159138.48107.7d.

Foulkes, J. D., Knowles, Z., Fairclough, S. J., Stratton, G., O' Dwyer, M., Ridgers, N. D., \& Foweather, L. (2015). Fundamental movement skills of preschool children in Northwest England. Perceptual Motor Skills, 121(1): 260-283. https://doi.org/10.2466/10.25.PMS.121c14x0.

Frömel, K., Stelzer, J., Groffik, D., \& Ernest, J. (2008). Physical activity of children ages 68: The beginning of school attendance. Journal of Research in Childhood Education, 23(1): 29-40. https://doi.org/10.1080/02568540809594644.

Giagazoglou, P. (2013). The interaction effect of gender and socioeconomic status on development of preschool-aged children in Greece. Infants $\mathcal{E}$ Young Children, 26(2): 177-186. https://doi.org/10.1097/IYC.0b013e318283bfb8.

Giagazoglou, P., Kabitsis, N., Kokaridas, D., Zaragas, C., Katartzi, E., \& Kabitsis, C. (2011). The movement assessment battery in Greek preschoolers: The impact of age, gender, birth order, and physical activity on motor outcome. Research in Developmental Disabilities, 32(6):

2577-2582.

https://doi.org/10.1016/j.ridd.2011.06.020.

Hardy, L. L., King, L., Farrell, L., Macniven, R., \& Howlett, S. (2010). Fundamental movement skills among Australian preschool children. Journal of Science and Medicine in Sport, 13: 503-508. https://doi.org/10.1016/j.jsams.2009.05.010.

Karim, A. E. A., \& Mohammed, A. H. (2015). Effectiveness of sensory integration program in motor skills in children with autism. The Egyptian Journal of Medical Human Genetics, 16: 375-380. https://doi.org/10.1016/j.ejmhg.2014.12.008.

Kourtessis, T., Tsougou, E., Maheridou, M., Tsigilis, N., Psalti, M., \& Kioumourtzoglou, E. (2008). Developmental coordination disorder in early childhood - A preliminary epidemiological study in Greek schools. International Journal of Medicine, 1(2): 9599.

Livesey, D., Coleman, R., \& Piek, J. (2007). Performance on the movement assessment battery for children by Australian 3- to 5-year-old children. Child: Care, Health and Development, 33(6): 713-719. https://doi.org/10.1111/j.1365-2214.2007.00733.x. 
Niklasson, M., Norlander, T., Niklasson, I., \& Rasmussen, P. (2017). Catching-up: Children with developmental coordination disorder compared to healthy children before and after sensorimotor therapy. PLoS ONE, 12(10), e0186126, https://doi.org/10.1371/journal.pone.0186126.

Nonis, K. P., \& Jernice, T. S. Y. (2014). The gross motor skills of children with mild learning disabilities. International Journal of Special Education, 29(2): 92-97.

Saraiva, L., Rodrigues, L. P., Cordovil, R., \& Barreiros, J. (2013). Motor profile of Portuguese preschool children on the Peabody Developmental Motor Scales-2: A cross-cultural study. Research in Developmental Disabilities, 34(6): 1966-1973. https://doi.org/10.1016/j.ridd.2013.03.010.

Spessato, B. C., Gabbard, C., Valentini, N., \& Rudisill, M. (2013). Gender differences in Brazilian children's fundamental movement skill performance. Early Child Development and Care, 183(7): 916-923. https://doi.org/10.1080/03004430.2012.689761.

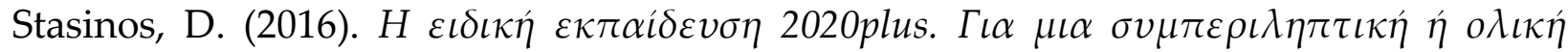

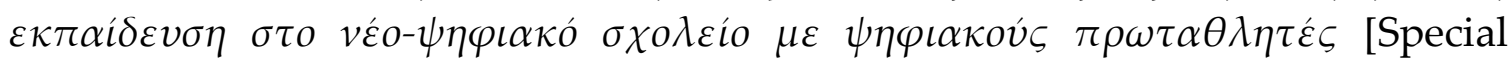
education 2020plus. For inclusive or total education at the new digital school with digital champions]. Athens: Papazisis.

Tieman, B. L., Palisano, R. J., \& Sutlive, A. C. (2005). Assessment of motor development and function in preschool children. Mental Retardation and Developmental Disabilities, Research Reviews, 11: 189-196. https://doi.org/10.1002/mrdd.20074

Valentini, N. C., \& Rudisill, M. E. (2004). Effectiveness of an inclusive mastery climate intervention on the motor skill development of children with and without disabilities. Adapted Physical Activity Quarterly, 21: 330-347. https://doi.org/10.1123/apaq.21.4.330.

Van Hartingsveldt, M. J., Cup, E. H., \& Oostendorp, R. A. (2005). Reliability and validity of the fine motor scale of the Peabody Developmental Motor Scales-2. Occupational Therapy International, 12(1): 1-13.

Venetsanou, F., \& Kambas, A. (2016). Motor proficiency in young children: A closer look at potential gender differences. SAGE Open, 1-10, https://doi.org/10.1177/2158244015626226.

Visser, L., Ruiter, S. A. J., van der Meulen, B. F., Ruijssenaars, W. A. J. J. M., \& Timmerman, M. E. (2012). A review of standardized developmental assessment instruments for young children and their applicability for children with special needs. Journal of Cognitive Education and Psychology, 11(2): 102-127. https://doi.org/10.1891/1945-8959.11.2.102

Wang, J. H-T. (2004). A study on gross motor skills of preschool children. Journal of Research in Childhood Education, 19(1): 32-43. https://doi.org/10.1080/02568540409595052

Zawi, K., Lian, D. K. C., \& Abdullah, R. T. (2014). Gross motor development of Malaysian hearing impaired male pre- and early school children. International Education Studies, 7(13): 242-252. http://dx.doi.org/10.5539/ies.v7n13p242 
Creative Commons licensing terms

Authors will retain the copyright of their published articles agreeing that a Creative Commons Attribution 4.0 International License (CC BY 4.0) terms will be applied to their work. Under the terms of this license, no permission is required from the author(s) or publisher for members of the community to copy, distribute, transmit or adapt the article content, providing a proper, prominent and unambiguous attribution to the authors in a manner that makes clear that the materials are being reused under permission of a Creative Commons License. Views, opinions and conclusions expressed in this research article are views, opinions and conclusions of the author(s). Open Access Publishing Group and European Journal of Physical Education and Sport Science shall not be responsible or answerable for any loss, damage or liability caused in relation to/arising out of conflict of interests, copyright violations and inappropriate or inaccurate use of any kind content related or integrated on the research work. All the published works are meeting the Open Access Publishing requirements and can be freely accessed, shared, modified, distributed and used in educational, commercial and non-commercial purposes under a Creative Commons attribution 4.0 International License (CC BY 4.0). 